\title{
Avaliação da força de tração em braquetes colados pela técnica indireta com diferentes sistemas de adesão
}

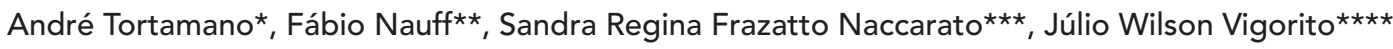

\section{Resumo}

Objetivo: o objetivo do presente estudo foi avaliar a resistência à tração de braquetes ortodônticos colados pela técnica indireta e pela técnica direta convencional. Metodologia: foram utilizados 50 pré-molares humanos íntegros, recém-extraídos por motivos ortodônticos. Esses dentes foram divididos em 5 grupos, nos quais foram colados braquetes ortodônticos metálicos (Abzil-Brasil) com as resinas compostas ortodônticas Concise (3M-Unitek-EUA) e Transbond XT (3M-Unitek-EUA) - utilizadas em ambas as técnicas, direta e indireta e Transbond Sondhi (3M-Unitek-EUA) - desenvolvida exclusivamente para a técnica indireta. O grupo I (controle I) foi objeto de colagem direta com Transbond XT; no grupo II (controle II) procedeu-se à colagem direta com Concise o grupo III recebeu colagem indireta com Concise; o grupo IV foi submetido à colagem indireta com Transbond XT e no grupo V foi realizada colagem indireta com Transbond Sondhi. Na técnica direta, o braquete foi colado diretamente sobre o esmalte após condicionamento ácido e aplicação de adesivo. Na técnica indireta, os braquetes foram colados primeiramente sobre modelo de gesso e depois transferidos para o dente, com o auxílio de moldeira individualizada. Os corpos-de-prova foram submetidos a testes de tração (Instron 4400) e os resultados foram objeto de testes estatísticos de análise de variância e de Tukey a 1\%. Resultados: os grupos III e V revelaram resultados significantemente menores que os dos dois grupos controles. Conclusão: a força obtida na colagem indireta com a resina Transbond XT não difere da força obtida na colagem direta com as resinas Concise e Transbond XT.

Palavras-chave: Ortodontia. Colagem indireta. Força de adesão.

\section{INTRODUÇÃO}

A colagem de braquetes na superfície do esmalte dos dentes é um procedimento clínico que pode ser realizado de modo direto, posicionando- se o braquete diretamente na superfície dentária ${ }^{8}$, ou indireto ${ }^{11}$ - constituído por duas etapas, uma laboratorial e outra clínica: na primeira etapa, os braquetes são posicionados no modelo e moldeiras

* Professor Assistente do Departamento de Ortodontia da Faculdade de Odontologia da Universidade de São Paulo.

** Especialista em Ortodontia pela FDCTO-USP.

*** Aluna do curso de especialização em Ortodontia da FDCTO-USP.

**** Professor Titular do Departamento de Ortodontia da Faculdade de Odontologia da Universidade de São Paulo. 
de transferência são confeccionadas; na segunda, os braquetes são posicionados nos dentes com o auxílio das moldeiras.

A colagem indireta é utilizada pelos ortodontistas por apresentar vantagens como: menor tempo clínico ${ }^{2,7}$, maior conforto para o paciente e maior precisão no posicionamento dos braquetes ${ }^{2,5,7}$. Em contrapartida, essa técnica também apresenta desvantagens, como tempo de trabalho laboratorial ${ }^{2}$, maior custo, maior número de etapas e a interface entre a resina para colagem e o adesivo aplicado ao dente ${ }^{14}$, que pode comprometer a adesão.

O correto posicionamento dos braquetes é facilitado pela colagem indireta, pois esta proporciona a visão dos dentes no modelo em todos os planos do espaço. Por mais eficiente que o ortodontista seja durante a colagem direta, esta não lhe proporciona a mesma visão ${ }^{7}$. A colagem indireta proporciona melhor posicionamento vertical dos braquetes $^{5}$, sendo mais eficaz em relação à angulação ${ }^{2}$. Porém nenhuma das técnicas promove $o$ posicionamento ideal dos braquetes ${ }^{5}$.

As falhas na adesão ocorrem com menor freqüência nos braquetes colados pela técnica direta, pois estes são posicionados mais próximos às superfícies dos dentes, neste tipo de colagem $^{14}$. Contudo, estudos ${ }^{9,10}$ relataram que a força de adesão obtida com a colagem indireta é suficiente para a sua utilização clínica. Ainda, outro estudo ${ }^{4}$ concluiu que não há diferença significante entre a força de adesão de braquetes colados direta ou indiretamente.

A remoção do braquete e da resina é facilitada ao final do tratamento ortodôntico quando os braquetes são colados pela técnica indireta, pois a interface criada entre a resina polimerizada e o adesivo torna-se a linha de fratura no momento da remoção dos braquetes ${ }^{13}$. A linha de fratura entre o esmalte e a resina ocorreu em $72 \%$ dos casos em que se utilizou a colagem indireta, e em $56 \%$ daqueles em que a colagem direta foi utilizada ${ }^{4}$.
O tempo de trabalho da colagem direta foi de 42,18 minutos e o tempo total demandado pela colagem indireta foi de 53,73 minutos, sendo que o tempo laboratorial foi de 20,82 minutos e o tempo clínico foi de apenas 23,91 minutos $^{2}$. A colagem indireta reduz em $40 \%$ o tempo do paciente na cadeira, porém o tempo total (clínico e laboratorial) é maior que o da técnica direta ${ }^{7}$.

O material utilizado para colagem indireta por Thomas ${ }^{13}$ e por Shiau et al. ${ }^{10}$ foi a resina Concise, nestes estudos a resina líquida $\mathrm{A}$ foi misturada à resina líquida $\mathrm{B}$ e essa mistura foi aplicada ao dente e ao braquete simultaneamente. A resina Concise também foi utilizada por Hocevar e Vincent $^{4}$, porém neste estudo a resina líquida $\mathrm{A}$ foi aplicada ao dente e a resina $\mathrm{B}$ ao braquete, depois a moldeira com os braquetes foi posicionada nos dentes e aguardou-se a polimerização da resina líquida. Resinas fotopolimerizáveis foram utilizadas para a colagem indireta por Read, O’Brien, Orth $^{9}$ e Mahony ${ }^{7}$.

Um adesivo próprio para a colagem indireta foi desenvolvido por Sondhi ${ }^{12}$. O adesivo é composto por dois componentes (um para ser colocado sobre a resina do braquete e outro sobre o dente), cuja mistura promove a polimerização. Além de apresentar tempo de polimerização inferior ao Concise, esse adesivo tem maior viscosidade, o que preenche pequenas irregularidades da resina já polimerizada no braquete ${ }^{12}$.

O presente trabalho teve como objetivo avaliar a força de adesão de braquetes colados através da técnica indireta com diferentes sistemas de adesão (adesivo mais resina): Transbond XT, Concise e Sondhi (3M-Unitek-EUA).

\section{MATERIAL E MÉTODOS}

Foram utilizados 50 pré-molares humanos, divididos em 5 grupos de 10 dentes, de acordo com a tabela 1 .

Nos dentes dos grupos I e II foi realizada profilaxia nas faces vestibulares do esmalte com escova de Robinson, pedra-pomes e água. As superfícies 
Tabela 1 - Grupos, técnica de colagem e material utilizado para a colagem.

\begin{tabular}{|c|c|c|}
\hline grupo & técnica de colagem & material \\
\hline grupo I & colagem direta & $\begin{array}{l}\text { Transbond e adesivo XT (3M- } \\
\text { Unitek-EUA) fotopolimerizável }\end{array}$ \\
\hline grupo II & colagem direta & $\begin{array}{c}\text { Concise (3M-Unitek-EUA) } \\
\text { autopolimerizável }\end{array}$ \\
\hline grupo III & colagem indireta & $\begin{array}{c}\text { Concise (3M-Unitek-EUA) } \\
\text { autopolimerizável }\end{array}$ \\
\hline grupo IV & colagem indireta & $\begin{array}{l}\text { Transbond e adesivo XT (3M- } \\
\text { Unitek-EUA) fotopolimerizável }\end{array}$ \\
\hline grupo V & colagem indireta & $\begin{array}{c}\text { Transbond e adesivo Sondhi } \\
\text { (3M-Unitek-EUA) } \\
\text { autopolimerizável }\end{array}$ \\
\hline
\end{tabular}

foram secas com jato de ar, passaram por condicionamento com ácido fosfórico a 35\% por 15 segundos e foram totalmente secas até atingirem coloração branca e opaca.

Os dentes do grupo I receberam uma fina camada do adesivo XT e uma porção de resina Transbond foi colocada nas bases dos braquetes, que foram posicionados nos centros das coroas clínicas; após a remoção dos excessos com sonda exploradora, o conjunto foi fotopolimerizado por 20 segundos, conforme especificação do fabricante.

Os dentes do grupo II receberam uma fina camada de adesivo Concise, de acordo com as instruções do fabricante, e em seguida os braquetes, que já estavam com resina Concise manipulada em suas bases, foram posicionados no centro das coroas clínicas dos dentes.

Os dentes dos grupos III, IV e V foram fixados com gesso-pedra em três bases diferentes, simulando a forma de um arco dentário (Fig. 1). Estas foram moldadas com alginato e os modelos foram cuidadosamente vazados com gesso especial (Fig. 2). Os modelos foram numerados como III, IV e V, de acordo com os grupos correspondentes, e receberam duas camadas de Cel-Lac como isolante.

Os braquetes do grupo III receberam uma camada de resina Concise, já manipulada de acordo com as especificações do fabricante, e foram posi- cionados nos dentes do modelo III. Os excessos de resina foram removidos e aguardou-se o tempo de polimerização da resina.

Os braquetes dos grupos IV e $\mathrm{V}$ receberam uma fina camada de resina Transbond em suas bases e foram posicionados no centro das coroas clínicas dos dentes dos modelos IV e V, respectivamente (Fig. 3). Após a remoção dos excessos, fotopolimerizou-se a resina de cada braquete por 20 segundos.

Foram confeccionadas moldeiras individualizadas para moldagem indireta em uma máquina de vácuo, utilizando uma lâmina de vinil siliconada flexível de $1 \mathrm{~mm}$, sobreposta por uma lâmina de PVC cristal rígida de espessura de $0,25 \mathrm{~mm}$. Foi confeccionada uma moldeira para cada modelo (Fig. 4). Os modelos foram hidratados por $90 \mathrm{mi}-$ nutos.

As moldeiras foram recortadas com estilete e disco de carborundum em baixa rotação e foram removidas dos modelos juntamente com os braquetes e a resina em suas bases (Fig. 5). Em seguida, o conjunto foi limpo com água, detergente e escova unitufo.

Os dentes que haviam sido fixados nas bases passaram por profilaxia com pedra-pomes e água, foram secos com jato de ar, receberam condicionamento com ácido fosfórico 35\% por 15 segundos e foram totalmente secos.

Os dentes do grupo III receberam uma camada do adesivo A do Concise e os braquetes receberam uma camada do adesivo B. A moldeira foi posicionada, aguardou-se a polimerização e foram removidas a lâmina rígida e depois a flexível (Fig. 6).

Uma camada de adesivo XT foi aplicada nos dentes e outra na resina dos braquetes do grupo IV. A moldeira foi colocada em posição e cada dente foi fotopolimerizado durante 15 segundos. Em seguida, as lâminas da moldeira foram removidas.

Os dentes do grupo $\mathrm{V}$ receberam uma camada do adesivo Sondhi específico para dentes e na resina dos braquetes foi aplicada uma camada do 


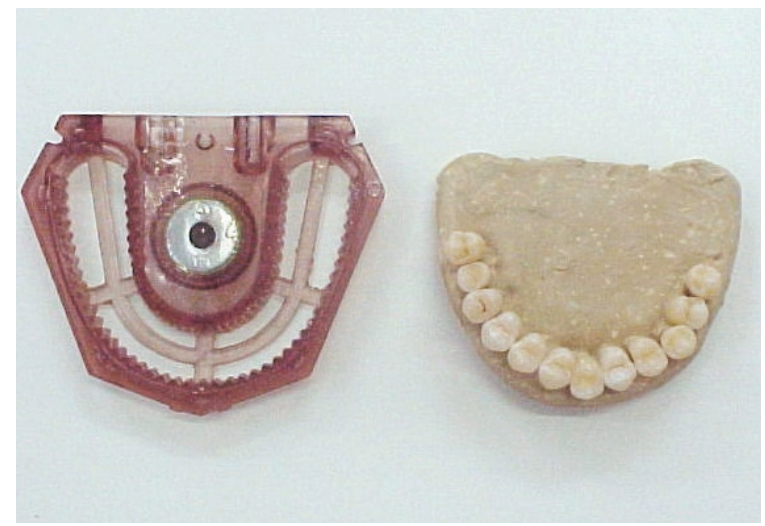

FIGURA 1 - Fixação dos dentes naturais, simulando a forma de um arco dentário.

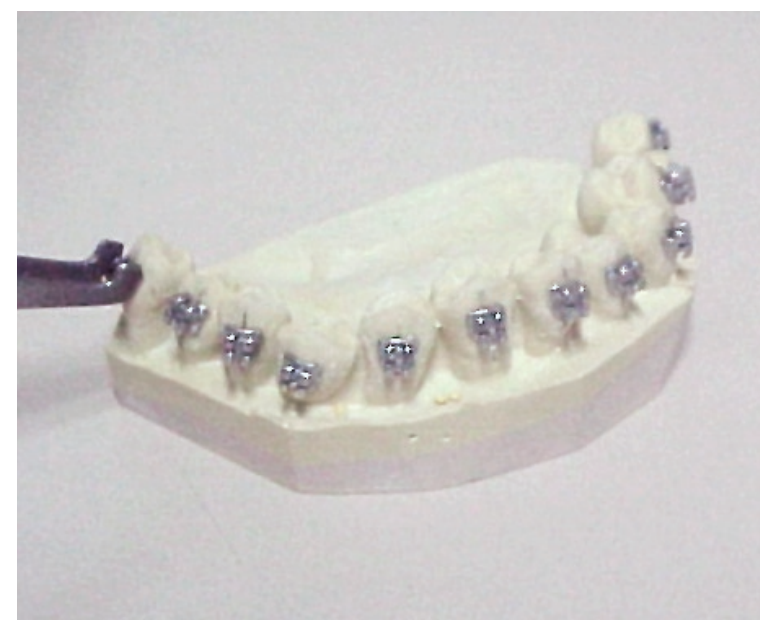

FIGURA 3 - Posicionamento dos braquetes nos modelos.

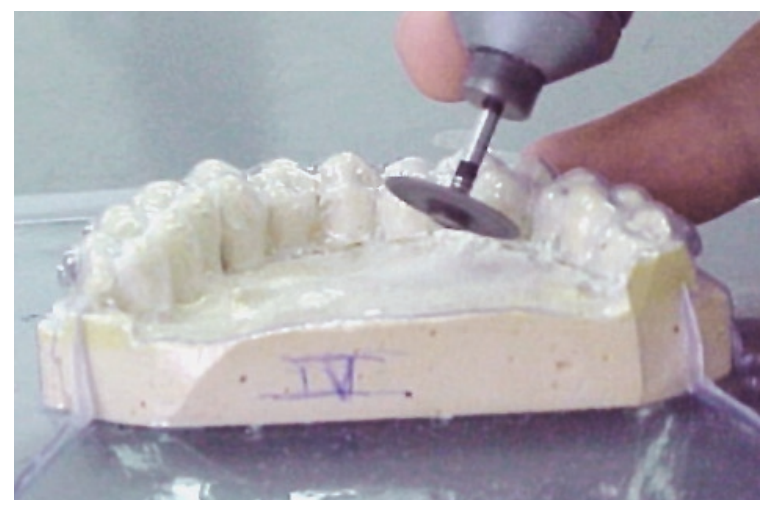

FIGURA 5 - Recorte da moldeira com disco de carborundum.

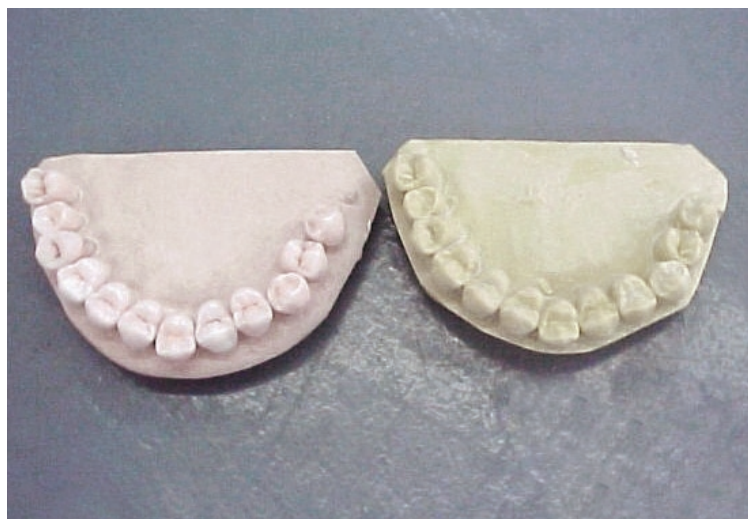

FIGURA 2 - Modelo de gesso resultante da duplicação do arco.

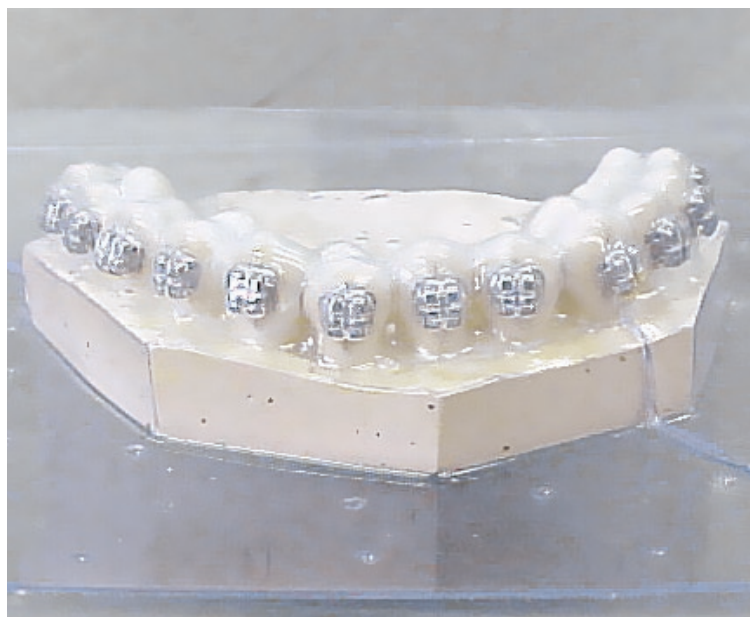

FIGURA 4 - Moldeira confeccionada sobre modelo.

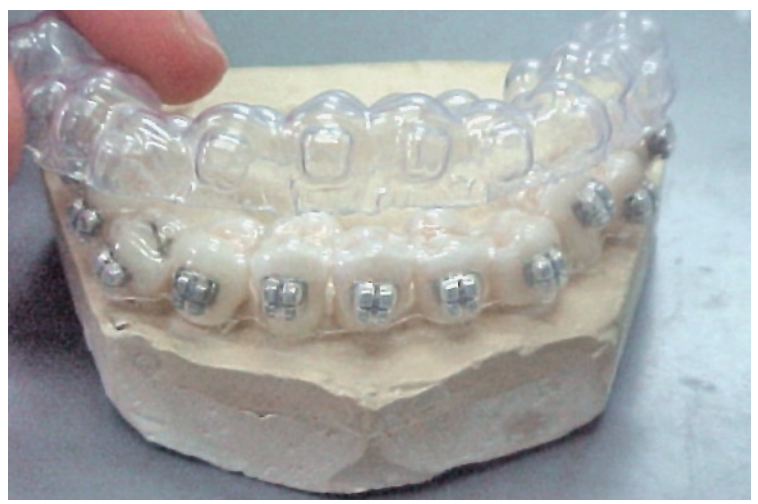

FIGURA 6 - Remoção das lâminas da moldeira em seqüência. 
outro adesivo Sondhi presente no kit. A seguir, a moldeira foi posicionada e aguardou-se a polimerização por 2 minutos e 30 segundos, conforme instruções do fabricante, após o que foram removidas as lâminas da moldeira.

Os dentes foram removidos das bases de gesso e incluídos em blocos de resina acrílica com seus longos eixos paralelos ao plano horizontal, com o auxílio de um delineador de prótese.

Os corpos-de-prova foram submetidos ao teste de tração (Instron 4400). A máquina de tração possui encaixe que se acopla aos braquetes dos corpos-de-prova posicionados paralelamente à sua base. Dessa forma, a força pode ser realizada com a direção do vetor de força perpendicular à superfície do esmalte, sem sofrer decomposição de vetores com direções diferentes, o que caracterizaria força de cisalhamento (Fig. 7).

Os valores originais do experimento, obtidos através da tração dos corpos-de-prova, foram con- vertidos de Newton para Megapascal em função da área - previamente calculada - da base do braquete.

Os resultados foram submetidos à análise estatística. Optou-se pela análise de variância, que revelou diferenças estatisticamente significantes entre os grupos.

\section{RESULTADOS}

Os grupos controle e experimentais diferiram quanto à força de adesão dos braquetes colados $(\mathrm{F}=3,76 ; \mathrm{p}<0,01)$. Devido à presença de diferenças estatísticas significantes entre as amostras, utilizou-se o teste Tukey para avaliar quais grupos apresentavam diferenças estatísticas ao nível de $1 \%$. O valor crítico de Tukey calculado a $1 \%$ foi de 4,57 .

As médias e os desvios-padrão, bem como o resultado do teste de Tukey, estão apresentados na tabela 2.

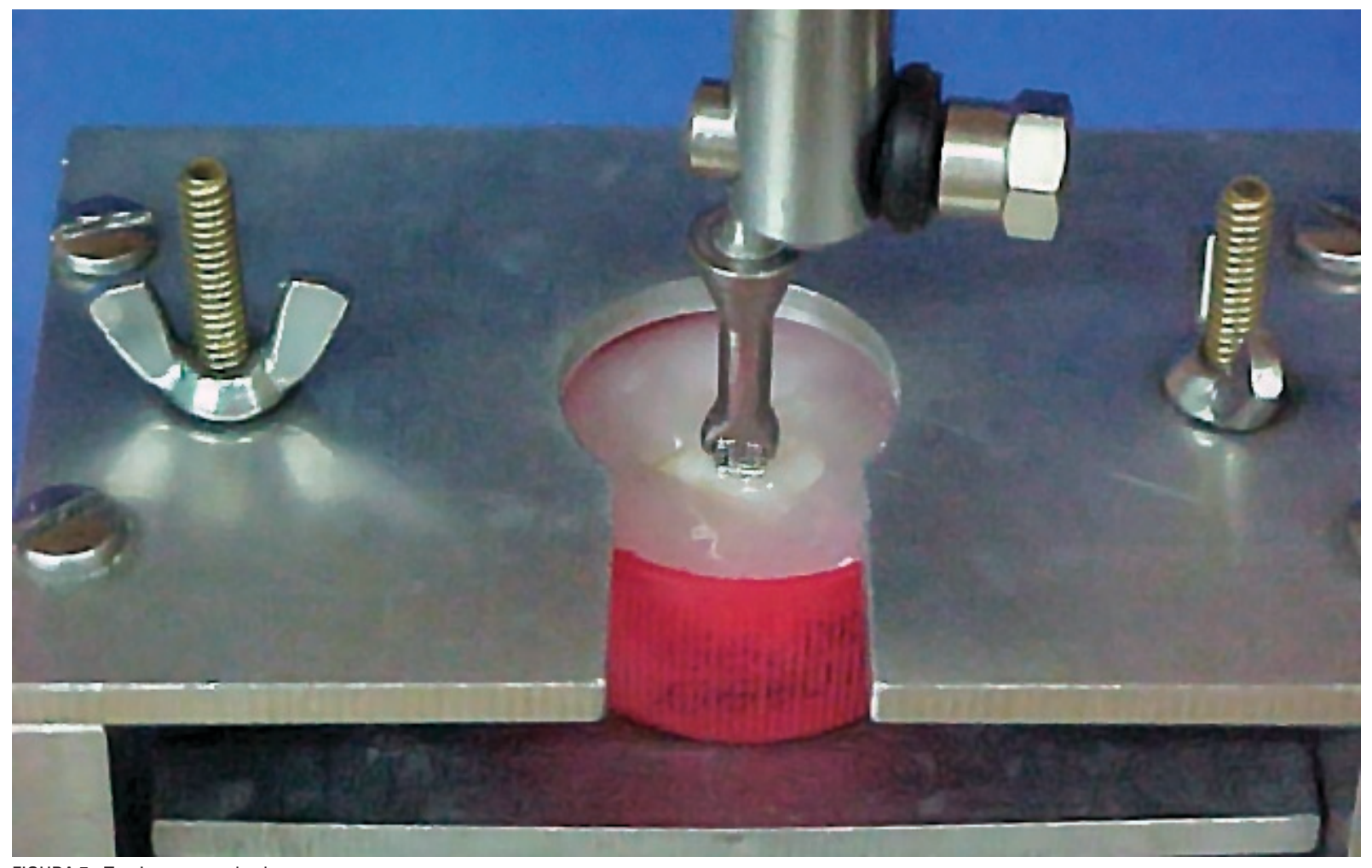

FIGURA 7 - Tracionamento dos braquetes. 
Tabela 2 - Médias amostrais do teste de resistência à tração.

\begin{tabular}{|c|c|c|c|}
\hline grupo & $\begin{array}{l}\text { médias amostrais } \\
\text { (em Mpa) }\end{array}$ & d.p. & Tukey* \\
\hline grupo I (Transbond) & 12,00 & 3,56 & A \\
\hline grupo II (Concise) & 11,61 & 2,74 & A \\
\hline $\begin{array}{c}\text { grupo III } \\
\text { (Concise-indireta) }\end{array}$ & 6,51 & 3,79 & B \\
\hline $\begin{array}{c}\text { grupo IV } \\
\text { (Transbond-indireta) }\end{array}$ & 8,49 & 1,83 & $A B$ \\
\hline $\begin{array}{c}\text { grupo V } \\
\text { (Sondhi-indireta) }\end{array}$ & 4,97 & 1,61 & B \\
\hline
\end{tabular}

De acordo com os resultados estatísticos, os grupos I, II e IV não apresentaram diferenças estatisticamente significantes, porém o grupo I apresentou a maior média amostral, seguido pelo grupo II, ambos referentes à colagem direta. Os grupos III e $\mathrm{V}$ apresentaram diferenças estatisticamente significantes em relação aos grupos I e II (controles I e II), mas, quando comparados ao grupo IV, não revelaram diferença estatisticamente significante.

\section{DISCUSSÃO}

A técnica de colagem e o material utilizado para a colagem devem promover adesão suficiente entre os braquetes e os dentes, suportando a aplicação das forças durante o tratamento ortodôntico. A resina quimicamente ativada Concise e a resina fotoativada Transbond XT foram consideradas grupos controles, por apresentarem bons resultados clínicos e científicos ${ }^{3,6}$.

O grupo III (Concise-indireta) apresentou resultados estatisticamente inferiores àqueles do grupo II (Concise-direta), contudo em um estudo anterior $^{4}$ não houve diferença significante entre a força de adesão de braquetes colados direta ou indiretamente com a resina Concise.

Foi preconizado que o valor aceitável clinicamente para a força de adesão dos braquetes nos testes de tração é de $5,4 \mathrm{Mpa}^{1}$; desta forma, como no presente trabalho a colagem indireta com a resina Concise obteve média de 6,514Mpa nos testes de tração, sua utilização clínica é aceitável.
Esta afirmação corrobora os resultados obtidos por Shiau et al. ${ }^{10}$

O grupo V (Sondhi-indireta) apresentou média de 4,972Mpa nos testes de tração, resultado inferior aos 5,4Mpa, valor insuficiente para a força de adesão entre braquetes e esmalte, segundo Aasrum et al. ${ }^{1}$ Porém, uma publicação anterior ${ }^{12}$ afirmou que a força de adesão obtida com a colagem indireta é suficiente para a sua utilização clínica.

Os resultados obtidos pelo grupo IV (Transbond XT-indireta) não apresentaram diferenças estatisticamente significantes em relação aos grupos controles, o que confirma a afirmação que a força de adesão obtida com a colagem indireta com resina fotopolimerizável é suficiente para a sua utilização clínica ${ }^{9}$.

Com o advento dos braquetes pré-ajustados, a precisão no posicionamento dos braquetes tornouse imprescindivel para o sucesso do tratamento ortodôntico ${ }^{12}$, a colagem indireta proporciona maior precisão no posicionamento dos braquetes que a colagem direta ${ }^{2,5,7}$. Contudo na colagem indireta há formação de um interface entre a resina que foi polimerizada no braquete e o adesivo aplicado ao dente no momento da colagem ${ }^{14}$, que poderia comprometer a adesão. Os resultados apresentados pelo presente trabalho confirmaram que a força de adesão obtida pela colagem indireta com a resina Transbond XT é suficiente para sua utilização clínica.

\section{CONCLUSÃO}

Nas condições de realização do presente experimento, foi possível concluir que:

1) A força de adesão obtida na colagem indireta com a resina Transbond XT não difere da força obtida na colagem direta com as resinas Concise e Transbond XT.

2) A resina ortodôntica Concise e a resina Sondhi usadas na colagem indireta proporcionam menor força de adesão que as resinas Transbond XT e Concise utilizadas na colagem direta.

Enviado em: fevereiro de 2004 Revisado e aceito: julho de 2004 


\title{
Evaluation of tensile strength of brackets bonded by indirect technique
}

\begin{abstract}
Aim: The purpose of this study was to evaluate the bonding strength of brackets for direct and indirect bonding techniques. Methods: Were used 50 human premolars recently extracted for orthodontic reasons. These teeth were divided in 5 groups and metalic orthodontic brackets (Abzil-Brazil) were bonded by direct and indirect techniques with orthodontic composite resins: group I (Control I) - direct bonding using Concise (3M-Unitek-EUA); group II (Control II) - direct bonding using Transbond (3M-Unitek-EUA) with XT bond system; group III - indirect bonding using Concise (3M-Unitek-EUA); group IV - indirect bonding using Transbond (3M-Unitek-EUA) with XT bonding system; group $V$ - indirect bonding using Transbond with Sondhi bonding system (3M-Unitek-EUA). The Sondhi bonding system was designed specifically for indirect bonding. In the direct bonding technique brackets were placed directly on the enamel surface, in the indirect technique brackets were first bonded in a cast of the teeth and then they were transfered by means of a tray to the teeth. The samples were submitted to tensile tests (Instron 4400) and the statistical ANOVA and Tukey (1\%) tests were applied. Results: The groups III and V showed lower bond strength than control groups (I and II), there was no significant difference between group IV and control groups (I and II). Conclusion: It was concluded that for indirect bonding technique only the Transbond XT (3M) didn't show significant statistical difference when compared to the direct bonding technique.
\end{abstract}

Key words: Orthodontics. Indirect bonding. Bond strength.

\section{REFERÊNCIAS}

1. AASRUM, E. et al. Tensile bond strength of orthodontic brackets bonded with a fluoride-releasing light-curing adhesive: an in vitro comparative study. Am. J. Orthod. Dentofacial Orthop., St. Louis, v. 104, no. 1, p. 48-50, July 1993.

2. AGUIRRE, M. J.; KING, G. J.; WALDRON, J. M. Assessment of bracket placement and bonding to indirect bonding techniques. Am. J. Orthod., St. Louis, v. 82, no. 4, p. 269-276, 1982.

3. BISHARA, S. M.; OLSEN, M. E.; DAMON, P.; JAKOBSEN, J. R. Evaluation of a new light-cured orthodontic bonding adhesive. Am. J. Orthod. Dentofacial Orthop., St. Louis, v. 114, no. 1, p. 80-87, 1998

4. HOCEVAR, R. A.; VINCENT, H. F. Indirect versus direct bonding: bond and failure location. Am. J. Orthod. Dentofacial Orthop., St. Louis, v. 94, p. 367-371, 1988.

5. KOO, B. C.; CHUNG, C. H.; VANARSDALL, R. L. Comparison of the accuracy of bracket placement between direct and indirect bonding techniques. Am. J. Orthod. Dentofacial Orthop., St. Louis, v. 116, no. 3, p. 346-351, 1999.

6. LUJAN, A. J. P. Estudo comparativo da capacidade adesiva de braquetes metálicos e de policarbonato em pré-molares humanos extraídos após diferentes períodos de armazenagem quando submetidos a testes de tração. 1996. Dissertação (Mestrado)- Faculdade de Odontologia da Universidade de São Paulo, São Paulo, 1996

7. MAHONY, D. An update on the indirect-bonding technique (non-custom base). J. Gen. Orthod., Milwaukee, v. 10, no. 3 p. 7-14, 1999

8. NEWMAN, G. V. Epoxy adhesives for orthodontic attachments, progress report. Am. J. Orthod., St. Louis, v. 51, p. 901-902, 1965.
9. READ, M. J. F.; O'BRIEN, K. D.; ORTH, D. A. Clinical trial of an indirect bonding technique with a visible light-cured adhesive. Am. J. Orthod. Dentofacial Orthop., St. Louis, v. 98, no. 3 p. 259-262, 1990.

10. SHIAU, J. et al. Bond strength of aged composites placed by an indirect technique. Angle Orthod., Appleton, v. 63, no. 3, p. 213-220, Sept. 1992

11. SILVERMAN, E.; COHEN, M.; GIANELLY, A. A.; DIETZ, V. S A universal direct bonding system for both metal and plastic brackets. Am. J. Orthod., St. Louis, v. 62, p. 236-244, 1972.

12. SONDHI, A. Efficient and effective indirect bonding. Am. J. Orthod. Dentofacial Orthop., St. Louis, v. 115, no. 4, p. 352359, 1999

13. THOMAS, R. G. Indirect bonding/ simplicity in action. J. Clin. Orthod., Boulder, v. 13, p. 93-105, 1979.

14. ZACHRISSON, B. U.; BROBAKKEN, B. O. Clinical comparison of direct versus indirect bonding with different bracket types and adhesives. Am. J. Orthod., St. Louis, v. 74, p. 62-78, 1978.

\section{Endereço para correspondência}

André Tortamano

Av. Prof. Lineu Prestes, 2227 - Cidade Universitária

CEP: 05.508-900, São Paulo / SP

E-mail: andretor@usp.br 